\title{
Measuring work engagement strategies and employees' behavioural outcomes in Nigerian Universities
}

\author{
Falola H.O \\ Oludayo O.A \\ Igbinoba E.E \\ Salau O.P \\ Borishade T.T
}

Department of Business Management

Covenant University, Ota, Ogun State, Nigeria

\begin{abstract}
Keywords
Employee's Engagement, career opportunities, recognition of efforts, job satisfaction, fun at work, structural equation modelling
\end{abstract}

\begin{abstract}
Institutions of higher learning in the modern and highly competitive academic environment compete to drive work engagement and explore possible means by which employees can develop and exhibit right attitudes and disposition to work. The main objective of this study was to examine the effect of work engagement strategies on employees' behavioural outcomes. Few studies analysed how work engagement strategies could help in driving standard work behaviour particularly in higher institutions. In an attempt to bridge this gap, this study was carried out using descriptive research method and Structural Equation Model (AMOS 22) for the analysis of four hundred and forty-one (441) valid questionnaire which were completed by the faculty members of the six selected private universities in Nigeria using stratified and simple random sampling techniques. Factor model which shows high-reliability and good fit was generated, while construct validity was provided through convergent and discriminant analyses. The findings indicate that career opportunities, recognition of efforts, institution's reputation, investment in employees and fun at work have positive influence on job satisfaction, job involvement and employees' loyalty. This study contributes to the scientific knowledge in the area of Strategic Human Resources Management and the insight discovered from the study would help the management of institutions of higher learning to improve their employees' level of engagement as well as their behavioural outcomes.
\end{abstract}

Corresponding author: Hezakiah Falola

Email addresses for corresponding author: hezekiah.falola@covenantuniversity.edu.ng

First submission received: $12^{\text {th }}$ January 2018

Revised submission received: $25^{\text {th }}$ March 2018

Accepted: 20th April 2018

\subsection{Introduction}

The complexity and increased competition in the $21^{\text {st }}$ century organisations have led to a need for strategic work engagement in the world of work. Work engagement strategy is fundamental to the continuous existence and sustainable development of institution of higher learning in the face of increasingly competitive academic environment (Gupta \& Shaheen, 2017). Institutions of higher learning are saddled with the responsibility of developing and raising new generation of leaders who are adequately equipped both mentally and morally to contribute meaningfully to organisations and society at large (Jena \& Pradhan, 2017). This can only be achieved with the availability of competent and skilled faculty members that are productively engaged and committed to teaching, research and innovation. Therefore, the driving force of work engagement cannot be over emphasized. This defines the relationships between the organisation and its workforce, thus, an "engaged employee" is one who is physically, psychologically, socially, intellectually and emotionally fascinated and passionate about work (Hakanen, Schaufeli \& Ahola, 2008) and they also strive to protect the interests and values of the organisation (Olivier \& Rothmann 2007). 
Strategic engagement of employees remains sine-qua-non for building appropriate work behaviour and disposition in higher institutions (Cain, Tanford, \& Shulga, 2018; Eldor \& Harpaz, 2016). Institutions of higher learning are striving to gain competitive edge which can only be achieved when employees perceive that there are career opportunities, recognition of efforts, readiness of the institution to invest in their employee in form of training, development and empowerment, fun at work, clear direction. All these will drive motivation, job satisfaction, involvement and loyalty (Ogbonnaya, Daniels \& Nielsen, 2017; Peterson, Nansook \& Seligman, 2005; May, Gilson \& Harter, 2004; Schaufeli \& Bakker, 2004). Employees' also tend to be more productively engaged if they are given the privilege to participate in decision making process and empowered to take initiative and responsibility (Nelson \& Simmons, 2003). Employees will also be more productively engaged, if encouraged to be actively involved in work processes and invigorated into organisations culture and practices (Vance, 2006, Gupta \& Shaheen, 2017). As noted by some scholars, for any institution of higher learning to survive in the competitive academic environment, it is expedient for such institution to cherish, motivate and develop employees in order to earn their commitment thereby steering the organisation to success (Olaniyan \& Hystad, 2016. Flock, 2010; Desai, Majumdar and Prabhu, 2010; Bassi and McMurrer, 2007).

Researchers have carried out studies on different elements of strategic human resource management such as talent management, employees' development, career development, knowledge management, employees' engagement among others (Jena and Pradhan, 2017; Sharma, Agarwal and Ganjiwale, 2011; Harathova 2009; Bhamagar, 2008; Macey and Schneider, 2008; Powell and Lubitsh, 2007; Saks, 2006; Schweyer, 2004). In spite of the attention given to employee engagement strategies, some organisations still find it difficult to engage their employees productively particularly in institutions of higher learning in Nigeria. Base on the foregoing, this paper seeks to investigate the influence of work engagement strategies on employees' behavioural outcomes. Therefore, the significance of this study emanated from the following specific objectives: (i) determine how career opportunities affect job satisfaction; (ii) analyse how recognition of effort affects employee's involvement; (iii) evaluate the influence of company reputation on employees' loyalty; (iv) investigate ways by which investment on employees will influence job involvement and (v) examine the role of fun at work on job satisfaction.

To achieve the above-mentioned specific objectives, the first section of this study focuses on the variables under investigation. The second section deals with methodology aspect which includes model specification, data collection procedure and data analysis, while data analysis, discussion and interpretation of the findings, conclusions and limitations and suggestions for further studies are discussed in the last part of the article.

\subsection{Literature Review \\ 2.1 Work Engagement}

Work Engagement has been described by many scholars' base on their views and perspectives. Ogbonnaya, Daniels and Nielsen (2017) described work engagement as a process by which the human resources of an organisation are economically and strategically inspired to be involved and committed to the organisational goals and values. In a related development, work engagement is the level at which employees are purposefully involved and satisfied with enthusiasm for work (Osborne and Hammoud, 2017; Harter, 2002), which drives employees' willingness to work beyond expectations to see that the organisation succeeds and achieve its goals on record time (Mani, 2011). Gupta and Shaheen (2017) and Seijts, and Crim (2006) posited that work engagement involves what he termed "10c" namely, "connection, career, clarity, convey, congratulate, contribute, control and collaborate, credibility and confidence".

Engaged employees see work as play or fun and they come to work every day with a sense of belonging, feeling a connection to their organisation, high level of enthusiasm and passion for their work as well as acting as partners in progress with the organisation (Joo, Lim \& Kim, 2016, Kanik, Ishaq \& Mridula, 2018). Also, Miller (2012) opined that employee work engagement is determined by the degree of discretionary efforts of employees into any given task beyond the required effort, time and brainpower to get the job done on record time. Therefore, work engagement is a positive attitude towards one's work which comprises a perception of mental enablement, feelings of vigour, preoccupation, dedication and enthusiasm to act, both within and extra-role towards the actualisation of organisational goals (Harju, 
Hakanen, \& Schaufeli, 2016; Witemeyer, 2013). Employees who are actively engaged are positive with their work, aware of business context, work harmoniously with their co-workers, and prepare to go beyond the ordinary effort to get job done thereby, enhancing productivity (Desai, et al., 2010). Work engagement can, therefore, be referred to as positive feeling and attitudes that employees have towards their jobs as well as discretionary effort they put into given responsibility (Falcone, 2006; Macey \& Schneider, 2008; McBain, 2007).

Work engagement is a strategic business tool for organisational success (Jena \& Pradhan, 2017; Lockwood, 2007) and reduces turnover and increases focus. Great leadership generates increased employee work engagement that results in organisational performance (Harter, Schmidt \& Hayes, 2002). Soyars, Maureen, Brusino and Justin (2009) opined that contributions, connections, and growth/advancement are the three elements that drives employees' engagement. Meanwhile, physical component, emotional component, psychological empowerment, cognitive component is dimensional concept of work engagement (Attridge, 2009; Shaw 2005; May, et al., 2004; Baumruk 2004; Markos \& Sridevi, 2010; Richman 2006).

\subsection{Factors Influencing Employees' Active Engagement}

Every organisation is dynamic and unique and what derives work engagement differs depending on the nature and the peculiarity of the organisation. In an attempt to know the influence of active employees' engagement, several factors have been studied as predictors such as perceived organisation support, equality, justice, rewards, care and concern for employees, trust, fairness recognition, harmonious relationship and interaction, freedom of communication, participation in decision making process, affective commitment, job fit among others (Desai, et al., 2010; Shuck, 2010; McBain, 2007). It becomes imperative to state that work engagement is a strategic tool that will help in building a sustainable performance in the world of work. Management of such organisations are expected to create enabling work environment that will motivate and empower the workforce to be economically engaged in any given assignment (Macey \& Schneider, 2008). By implications, the effective work engagement depends on the pattern of the job strategies adopted by the management which are important for higher performance that will influence organisational success. In another development, work environment, leadership style, teamwork, training and career development, compensation and remuneration systems, organisational policies, work characteristics, self-confidence and fun at work among others are motivating driving force that influences employees' involvement, loyalty and satisfaction (Anitha, 2014; Bakker, Shimazu, Demerouti, Shimada \& Kawakami, 2014; Miller, 2012; Xu \& Thomas, 2011). Meanwhile, employees' engagement has been conceptualized and classified under trait engagement, state engagement or affective satisfaction, behavioural engagement and inspired engagement as depicted in figure 1 .

\subsection{Work Engagement Strategies}

As noted by Banhwa, Chipunza, and Chamisa, (2014) and Woodruffe (2006), training and manpower development, management support initiatives, employee's empowerment, effective communication, equality, job satisfaction, work-life balance, health and safety, appropriate reward system, equal opportunity and fair treatment etc. have been identified as effective strategic tools that can enhance employees effective work engagement. In a related development, Career opportunities, recognition, and organisation reputation enhance work engagement that drive commitment and optimal performance (Aon, 2013; Organ, Posdakoff \& MacKenzie, 2006). However, the proper application of these work engagement strategies will promote employees' loyalty, commitment, satisfaction etc. which will invariably culminate into productive, satisfactory and employees' retention (Kanik, Ishaq, \& Mridula, 2018; Schaufeli \& Bakker, 2004). Sequel to the review of the literatures, work engagement strategies comprises of career opportunities, employees' empowerment, management support, investment on employees, employees' participation in decision making, recognition and reward, work-life balance, fair treatment and equality, good relationship with supervisors and co-workers etc. (Banhwa, Chipunza \& Chamisa, (2014). These tend to influence employees' good attitude towards work and enhance employees' active engagement which will invariably culminate into efficient job performance. 


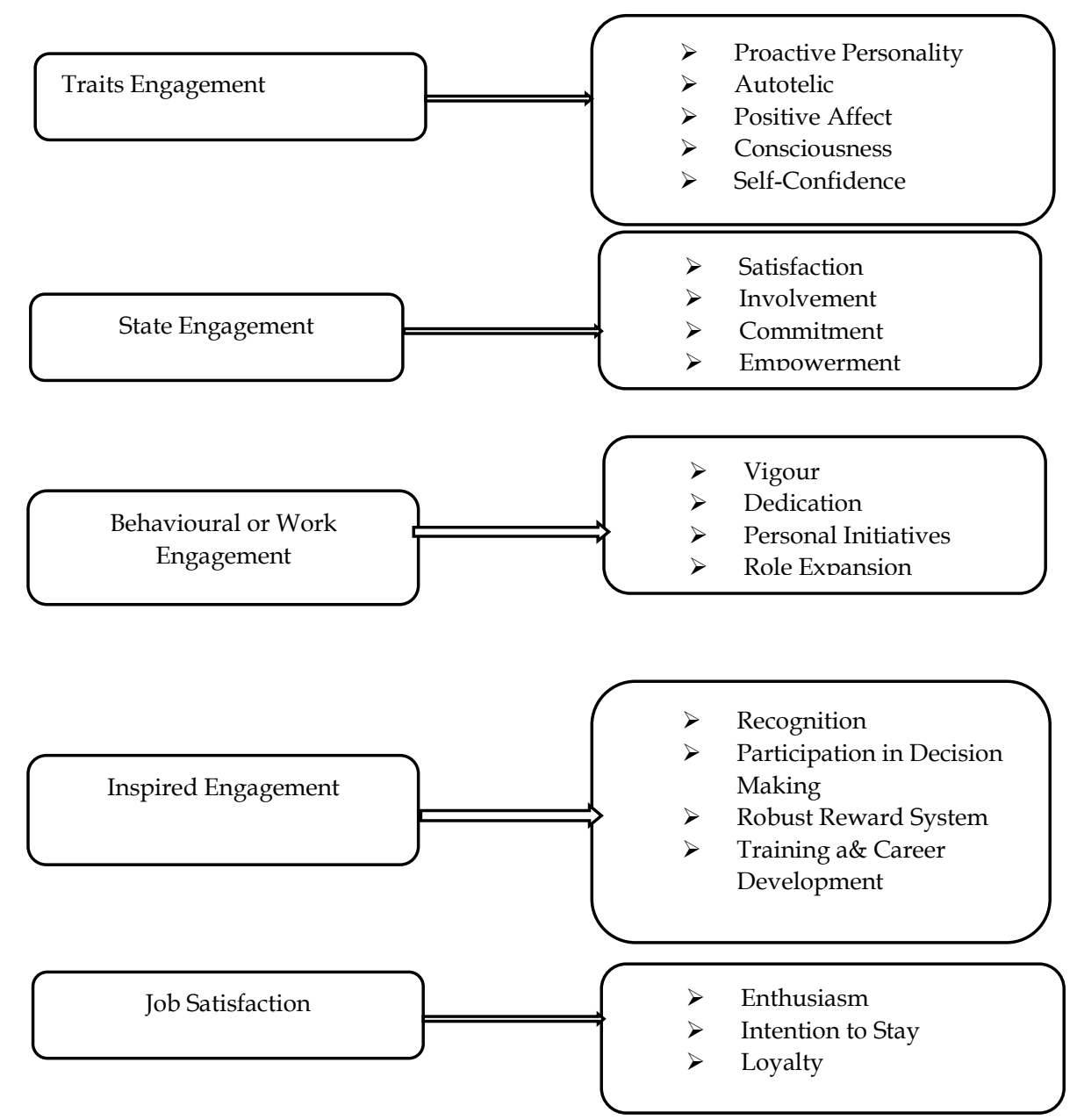

Figure 1: Classifications of Employees' Engagement

Source: Adapted from Macey and Schneider, (2008)

\subsection{Theoretical Framework}

Self-determination theory posits that employees tend to be actively engaged when they are intrinsically motivated (Deci \& Ryan, 1985). It is therefore the responsibility of management of organisations to focus on employees' engagement strategies that will help in building employees intrinsic motivation. The theory also posits that employees derive strength for productive engagement as a result of their ability to manage and control their personal behaviours and goals. This suggests that employees' behavioural outcome depends largely on the level of intrinsic motivation and job satisfaction which will invariably affect their performance. The motivation level of an employee is related to job satisfaction, involvement and loyalty to the organisation. All these are processed internally by the individual employee and it affects his or her emotional state of mind (Deci \& Ryan, 1985). To ensure that employees have positive mind set, organisations are expected to look into what can drive work engagement which include but not limited to career progression, employees support, the level of investment on employees, organisational reputation, fun at work, among others (Osborne \& Hammoud, 2017; Ogbonnaya, Daniels \& Nielsen, 2017). Therefore, according to the Self-determination theory, when employees perceive that their organisation is not doing anything to enhance their intrinsic motivation, they begin to gradually withdraw their commitment, hide their identities, ideas, and feelings. This will invariably have adverse effect on work performance (Deci \& Ryan, 1985). Similarly, if the employees are satisfied by the various engagement practices and loyal to the organisation, it can culminate into outstanding work engament (Blattner \& Walter, 2015; Bowen, 2016; Barrick, Thurgood, Smith, \& Courtright, 2014). According to Mowbray, Wilkinson and Tse (2014), the management of organisations including institutions of higher 
learning adopt the concept of Self-determination theory to encourage employees have progressive attitudes toward their organization.

\subsection{Methodology}

The goal of this research is to investigate the resultant effect of job engagement strategies on employees' behavioural outcomes. Job engagement strategies were measured using career opportunities, recognition of efforts, corporate reputation, investment in employee, fun at work. While employees' behavioural outcomes were measured using job satisfaction, employees' involvement and employees' loyalty. A descriptive design was adopted for this study. As suggested by Creswell (2003), a descriptive design enables researchers to adopt one-time observation, including proximate and conclusive variables fundamentally needed to discourse the problem of the research as highlighted in the study.

Meanwhile, Statistical Package for Social Sciences and AMOS 22 were used for the analysis while Structural Equation Modelling (SEM) was used to determine the strength of relationship and resultant effect of job engagement strategies and employees' behavioural outcomes. This is depicted in figure 1. Factor model which shows high-reliability and good fit was generated, however, construct validity was provided through convergent and discriminant analyses. The sample for this study consisted of 600 respondents across the top six private universities in Southwest, Nigeria. The selection of the participating universities was based on performance as ranked by various national and international ranking agencies. What informed the choice of Southwest Nigeria is because 48 percent of all private universities in Nigeria are situated within the geo-political zone while others spread across five geopolitical zones in Nigeria. The combination of stratified, purposeful and random sampling techniques was adopted for the purpose of this study. It is also imperative to report here that data for the study were obtained via self-structured questionnaire and modified items from the literature reviewed. The 5-point Likert scale that described the extent to which the respondents agreed to the statements on the research instrument was used. The choice of the 5-point Likert scale was based on it typicality as established by Bowling \& Hammond, (2008) which was also used in similar studies (Falola, Salau, Oyafunke-Omoniyi \& Olokundun, 2016, Osibanjo, Salau, Falola, Oyewunmi, 2016, Ibidunni, Osibanjo, Adeniji, Salau \& Falola, 2016). Data were also studied and the assumptions for analysis were checked based on the procedures recommended by Anderson and Tatham (2009). It was discovered that data presented were precise and accurate with no inconsistencies in various measures. It must also be noted that acceptance values and variance inflation factor values were the threshold $>0.2$ and $>5.0$ respectively.

The researchers also analysed the normality and linearity while 159 respondents from the original sample of 600 were removed with the use of Mahalanobis Distance Criterion (MDC). The percentage of missing data was far less than 5 percent and were excluded using Listwise Deletion Method as suggested by Tabachnick and Fidell (2007) and Fornell and Larcker (1981). The final sample for the study was four hundred and forty-one (441) respondents which can also be considered accurate for the analysis. After the modification of the final measurement model for all constructs, unidimensionality, reliability, and validity were evaluated, and the outcomes measurement model are depicted in Table 1, summarizes the factor loadings, indicator reliability, error variance, compose reliability and average variance extracted estimate for the final measurement model. 


\subsection{Results}

Table 1: Result of Validity and Reliability

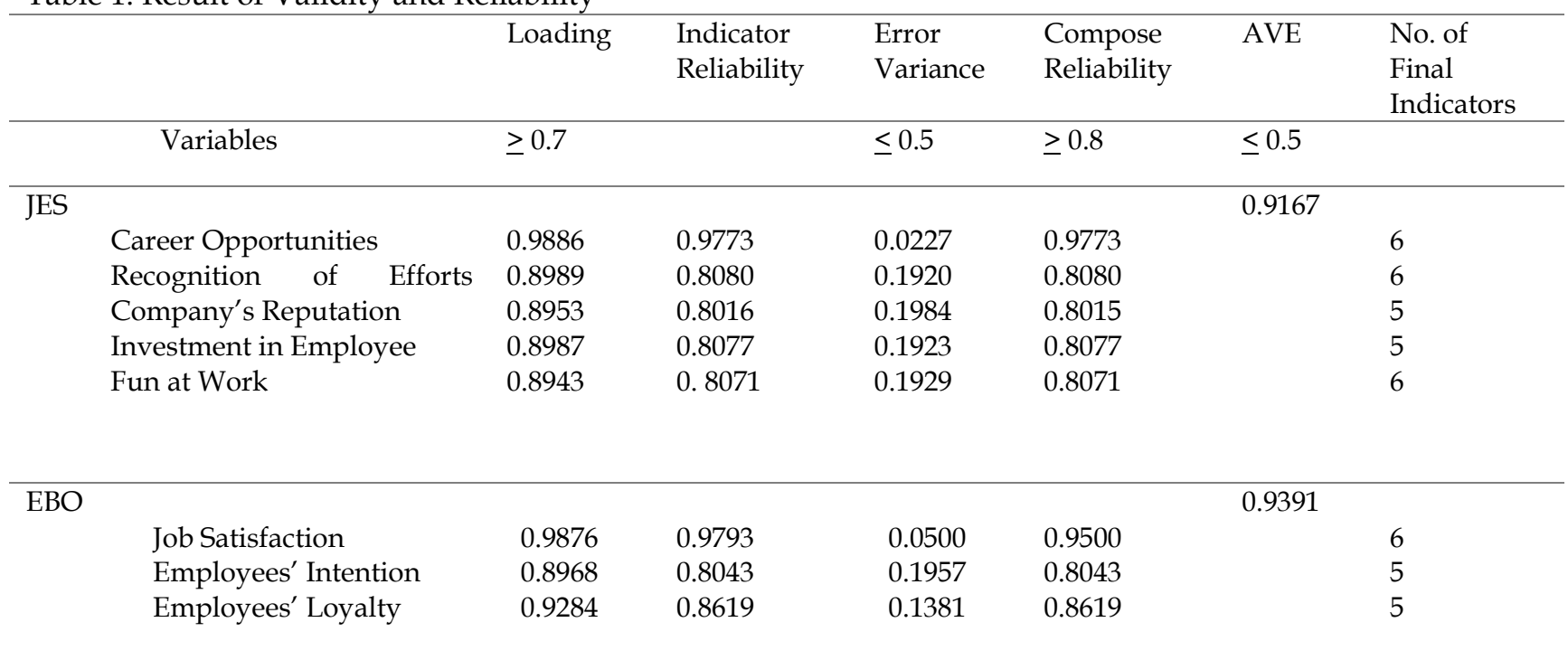

All loadings are significant at $\mathrm{p}<0.0001$.

The measurement model that is very paramount is the path significance indicated by the standardised regression estimate $(\beta)$ which measures the effects of independent variable on dependent variable. In order to determine the model, fit of the variables, several fit indices which include: chisquare/degree of freedom (X2/df), Goodness-of-Fit Index (GFI) Comparative Fit Index (CFI), and Root Mean Square Error of Approximation (RMSEA) were examined and the result is depicted in figure1.

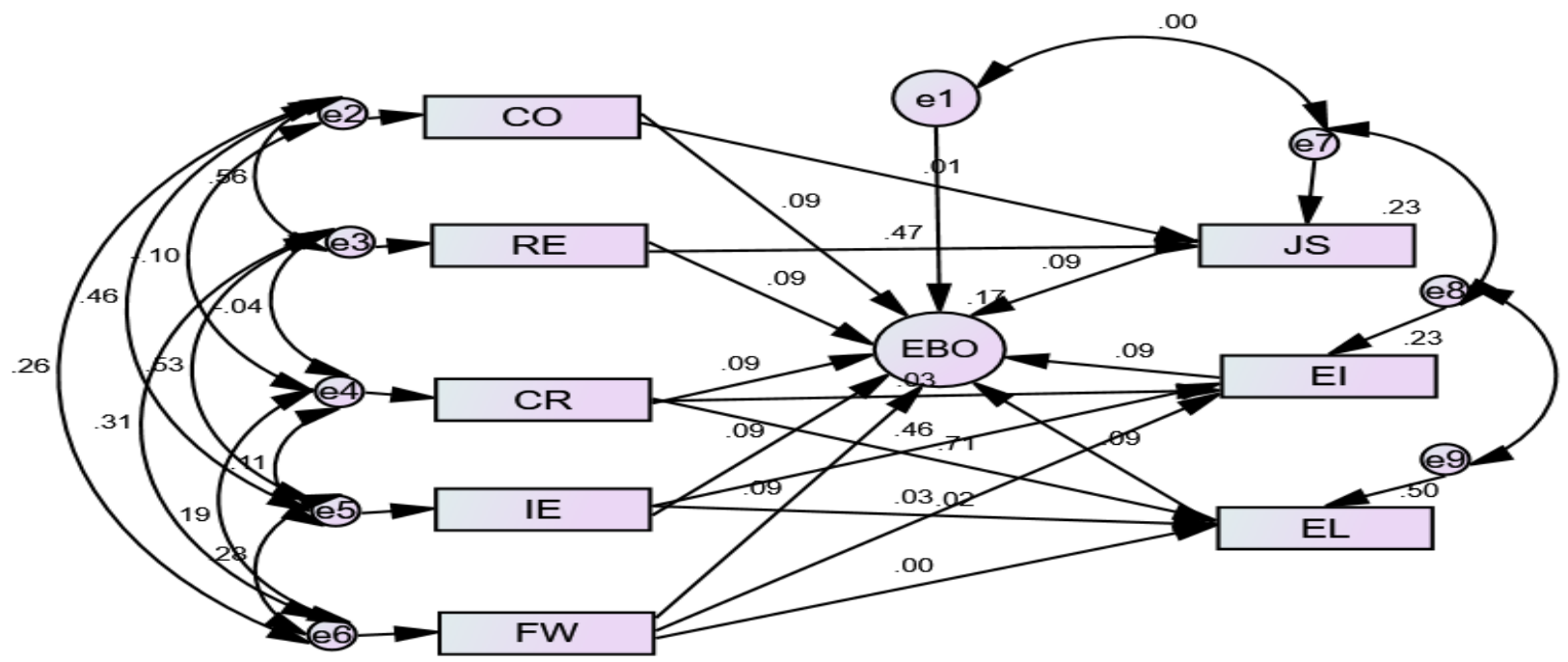

Parameters: $\mathrm{X}^{2}$ 41.173; $\mathrm{P}<0.001 ; \mathrm{IFI}=0.908 ; \mathrm{NFI}=0.988 ; \mathrm{CFI}=0.903$;

$\mathrm{GFI}=0.941 ; \mathrm{AGFI}=0.933 ; \mathrm{RMSEA}=.5623$

Figure 1: Job Engagement Driving Force and Employee Behavioural Outcome Model

JES- Job Engagement Strategies

CO - Career Opportunities; RE - Recognition of Efforts; CR - Corporate Reputation

IE - Investment on Employee; FW - Fun at Work

EBO - Employee Behavioural Outcomes

JS - Job Satisfaction; EI - Employee Intention; EL - Employee Loyalty 
Table 3: Regression Weights

\begin{tabular}{lllllll}
\hline & & & Estimate & S.E. & C.R. & P \\
\hline JS & $<---$ & CO & .006 & .087 & .064 & .949 \\
\hline JS & $<---$ & RE & .472 & .113 & 5.400 & $* * *$ \\
\hline EL & $<---$ & CR & .705 & .060 & 11.970 & $* * *$ \\
\hline EL & $<---$ & IE & .023 & .064 & .390 & .697 \\
\hline EI & $<---$ & IE & .464 & .086 & 5.921 & $* * *$ \\
\hline EI & $<---$ & CR & .030 & .078 & .398 & .691 \\
\hline EI & $<---$ & FW & .027 & .080 & .353 & .724 \\
\hline EL & $<---$ & FW & .004 & .062 & .061 & .951 \\
\hline
\end{tabular}

Note: C.R. $=$ Critical Ratio; S.E. $=$ Standard Error; ${ }^{*}$ significant at 0.05

\subsection{Discussion of the Findings}

Further to Table 3, the regression weight between career opportunities in the prediction of employee job satisfaction show the path coefficient of $.006(\mathrm{p}<0.001)$. This suggests that when employee career opportunities go up by 1 standard deviation, the level of employee job satisfaction will go up by 0.006. The implication of this is that, if management of the institutions of higher learning give attention to the career opportunities, there is likelihood that it will impact on the employees' level of job satisfaction which will invariably enhance organisational performance particularly in this dynamic and competitive academic environment. This validates the findings of Eldor and Harpaz (2016) in their model of employee engagement, learning environment and job performance. Meanwhile, Gupta and Shaheen (2017) in their findings discovered that career opportunity is one of the driving forces of work engagement while Falola et al (2018) noted that career opportunities can foster Intrapreneurship employee performance. This suggests that work engagement has a significant influence on employees' job satisfaction and turnover intention. In a related development, the regression weight between recognition of effort and employee job satisfaction is $.472(\mathrm{p}<0.001)$ which indicates that when recognition of employees' effort goes up by 1 standard deviation, employee job satisfaction goes up by 0.472 . Therefore, organisations' readiness to recognise and reward efforts of the employees will likely rub-off on the employees' level of satisfaction. This corroborates the findings of Nuesch, (2017) who noted that recognition of effort is fundamental in building acceptable and appropriate workplace attitudes that will culminate in achieving the organisational strategic goals particularly in the highly competitive academic environment that is characterised by the evolvement of sophisticated technology.

The implication of this finding is that any institution of higher learning that is more sensitive to employees' performance and recognise such performances in the academic world-is more likely to attract and retain employees with distinctive capabilities that will be actively engaged in teaching, research and innovation. This finding is in line with the submission of Joo, Lim and Kim (2016) in their study on work engagement, psychological capital, and empowerment. This also correlates with the findings of Olaniyan and Hystad (2016) in their research work titled "employees' psychological capital, job satisfaction, insecurity, and intentions to quit: the direct and indirect effects of authentic leadership". The regression weight between institutions reputation in the prediction of employee involvement and employee loyalty are $.905(\mathrm{p}<0.001)$ and $.030(\mathrm{p}<0.001)$ respectively. This indicates that when institutions image goes up by 1 standard deviation, employees' involvement and loyalty go up by 0.905 and 0.030 standard deviations in that order. Any institution that wants to tap from the reservoir of its employees' potentials and earn their involvement and loyalty would need to look at what needs to be done in order to improve the institutional image. The findings are in line with Cain, Tanford, \& Shulga, (2018) and Osborne, Hammoud, (2017). They found out that employees tend to be effectively engaged in the workplace if they are comfortable with the image and reputation of the organisation.

Meanwhile, the regression weight for investment on employee in the prediction of employees' loyalty and employees' investment are $.023(\mathrm{p}<0.001)$ and $.464(\mathrm{p}<0.001)$ respectively. This suggests that when investment on employee goes up by 1 standard deviation, employee loyalty and employee job involvement will increase by 0.023 and 0.464 . The implication of this is that employees are likely to be fully involved and loyal to their institution if they have the feelings that the institutions is ready to invest on them in terms of training, conferences, development, to mention just a few. This finding is also in line 
with the submission of Shuck and Rose (2013) who noted that reframing employees' engagement within the context of meaning and purpose has significant implications for employees' loyalty and involvement when the institution does enough in investing on employees.

The implication of this is that, once the employees perceive that there is provision for investment on them by the institution in its policy and practice, this will make the employees to be more committed, loyal and satisfy with the organisation. This further suggests that the level of performance of employees will be trigged and sustained if the institution invests heavily on staff training and development. This finding also validates the submission of Blattner and Walter (2015) noting that creating and sustaining a highly engaged company culture can be achieved through investment on employees. The investment on employees could come inform of training, development, education among others. Also, the effect of fun at work in the prediction of employees' involvement and loyalty, show the path coefficient of $.027(\mathrm{p}<0.05)$ and $004(\mathrm{p}<0.05)$ in that order. Therefore, when fun at work goes up by 1standard deviation, employees' involvement and loyalty goes up by 0.027 and 0,004 respectively. The implication of this is that when employees enjoy fun at work, it will most likely affect their involvement and loyalty. The finding correlates with the findings of Jamaludin, Ahmad, Mohammad and Shobri (2016). They found out that fun at work in form of socializing with co-workers, celebrating achievements at work, personal freedom to celebrate and global fun at work make employees to be more engaged, involved and loyal to the organisation. Similarly, Fairhurstt (2013) also found out that fun at work has significant effect on employees' level of involvement and satisfaction. Sequel to the above, it is important to stress that career opportunities, recognition of efforts, company's reputation, investment on employee and fun are predictors of employees' behavioral outcomes such as job satisfaction, employees' involvement, and employees' loyalty.

\subsection{Conclusion}

Every organisation irrespective of its industrial experience, seeks to be more effective and gain competitive advantage, thus, the impact of employees' engagement strategy on job performance cannot be over emphasized. The need for improved efficiency in organisation has become generally accepted and this depends on efficient and effective engagement of employees in corporate activities. It becomes necessary in view of advancement in modern world to stimulate employees' involvement through their perceptions of the following features: job importance; career opportunities; simplicity of work expectations; employees' empowerment; steady feedback and dialogue with senior colleagues. In addition, employees' engagement can also be stimulated through quality of working relationships with peers, senior colleagues, and subordinates as well as perceptions of the character and ethics of the organisation. Others are effective internal employee communications and reward; and providing conducive work environment for greater commitment and higher performance. Management should create an enabling working environment; provide good leadership; allow opportunities for employees' personal goal and development, provide necessary support, involve the employees in decision making process; and give competitive remuneration and incentives. The above-mentioned strategies will propel the employees' discretionary behaviour thereby, enhancing their performance and significantly contributing to organisational development.

Meanwhile, practical recommendations can be given to the management of universities in Nigeria. In order to retain the faculty members with distinctive competences, the universities should enhance the work engagement of the employees. The value of the institutional supports will likely influence the behavioural outcomes of the employees. Similarly, work engagement can also be influenced if faculty members are given opportunities to participate in decision making process particularly on the issues that relate to work engagement. Theoretical recommendations are another contribution that this study has made. Further to the basic assumptions of self-determination theory, it is recommended that if the faculty members are given adequate and competitive reward and they are satisfied, it will increase their commitment, involvement and their level of engagement to research, teaching, innovation and community impact.

\subsection{Limitations and Suggestions for Further Studies}

The study was limited in scope as it covers only six (6) private universities in Southwest, Nigeria. The generalisation of the findings becomes a problem since there are other private universities in other 
five geo-political zones in Nigeria. It is recommended that further studies can expand the scope of the study. A comparative analysis between private universities and public universities across the six geopolitical zones can as well be carried out. In addition, it is possible that the relationship between employee work engagement and employee behaviour outcomes can be influenced by other factors. It is suggested that factors like performance incentives, institutional supports, demographic characteristics among others can be introduced as intervening variables. Besides, this study used qualitative method, it is recommended that future studies can adopt mixed method approach.

\section{Acknowledgement}

We would like to appreciate Covenant University Centre for Research, Innovation and Discovery for their financial support.

\section{References}

Anitha, J. (2014) Determinants of employee engagement and their impact on employee performance. International Journal of Productivity and Performance Management. 63(3) 308-323.

Armstrong, M. (2006) A handbook of human resource management practice (7thed.) London: Kogan Page.

Attridge, M. (2009) Measuring and managing employee work engagement: a review of the research and business literature. Journal of Workplace Behavioral Health. 24(1), 383-398.

AON Hewitt, (2013) Trends in global employee engagement. [online]. Retrieved from: www.aonhewitt.com.

Bakker, A.B., Shimazu, E. Demerouti, K.S \& Kawakami, N. (2014) Work engagement versus workaholism: A test of the spillover-crossover model. Journal of Managerial Psychology. 29(1), 63-80.

Babb, S. \& Meyer, T. (2005) Perspectives on learnerships. Knowledge resources. South Africa: Knowres.

Banhwa, P.F, Chipunza, C. \& Chamisa, S.F. (2014) The influence of organisational employee engagement strategies on organisational. Journal of Social Sciences, 5 (6), 53-62.

Barrick, M. Thurgood, G.R., Smith, T.A \& Courtright, S. (2014) Collective organizational engagement: Linking motivat ional antecedents, strategic implementation, and firm performance. Academy of Management Journal, 58,111-135.

Baumruk, R. (2004) The missing link: the role of employee engagement in business successes. Workspan, 47(5), 48-52.

Bassi, L, \& McMurrer, D. (2007) Maximizing Your Return on People. Harvard Business Review, March: 115 - 123.

Blattner, J., \& Walter, T.J. (2015) Creating and sustaining a highly engaged company culture in a multigenerational workplace. Strategic HR Review, 14, 124-130.

Cain, L., Tanford, S. \& Shulga, L. (2018) Customers' Perceptions of Employee Engagement: Fortifying the ServiceProfit Chain. International Journal of Hospitality \& Tourism Administration, 19(1).

Deci, E.L., \& Ryan, R.M. (1985). Intrinsic motivation and self-determination in human behavior. New York, NY: Plenum.

Desai, M., Majumdar, B., \& Prabhu, G.P. (2010) A Study on Employee Engagement in Two Indian Businesses. Asian Journal of Management Research, 1(1), 81-96.

Eldor, L., Harpaz, I. (2016) A process model of employee engagement: Learning climate and its relationship with work performance. Journal of Organizational Behaviour, 37(2), 213-235.

Endres, G. \& Mancheno-Smoak, L., (2008) The human resource craze: Human performance improvement and employee engagement. Organisation Development Journal, 26 (2), 69-78.

Falola, H.O., Salau, O.P., Olokundun, A.M., Omoniyi-Oyafunke, C.O, Ibidunni, A.O \& Oludayo, A.O. (2018). Employees' intrapreneurial engagement initiatives and its influence on organisational survival. Business: Theory and Practice, 19, 9-16.

Falola, H. O, Salau, O. P, Omoniyi-Oyafunke, C. O \& Olokundun M. A. (2016). Effect of marital instability on employees' performance in selected commercial banks in Nigeria. International Business Management. 10(21), 5158-5163.

Falola, H. O., Osibanjo O. A, \& Ojo, S.I. (2014) Effectiveness of training and development on employees' performance and organisation competitiveness in the Nigerian banking industry. Bulletin of the Transilvania University of Braşov Series V: Economic Sciences. 7(56).

Fairhurst, D. (2013) Work made fun gets done, sums up the preconditions of an engaged and productive workforce. HR Magazine, MA Business \& Leisure. 17.

Frank, F., Finnegan, R. \& Taylor, C. (2004) The race for talent: retaining and engaging workers in the 21st century. Human Resource Planning, 27(3), 12 - 26.

Gallup Organisation (2006) [online] Available at: www.gallup.com.

Gupta, M \& Shaheen, M. (2017) The impact of work engagement and turnover intention: Moderation by Psychological capitalin India. Business: Theory and Practice, 18(1), 136-143

Harju L.K, Hakanen, J.J, Schaufeli, W.B. (2016). Can job crafting reduce job boredom and increase work engagement? A three-year cross-lagged panel study. Journal of Vocational Behavior, 95:11-20. 
Hakanen, J.J., Schaufeli, W.B., \& Ahola, K. (2008) The job demands-resources model: a three-year cross-lagged study of burnout, depression, commitment, and work engagement. Work and Stress, 22(3), 224-241.

Ibidunni, O.S., Osibanjo, A.O., Adeniji, A.A., Salau, O.P. and Falola, H.O. (2016) Talent Retention and Organizational Performance: A Competitive Positioning in Nigerian Banking Sector. Periodica Polytechnica Social and Management Sciences, 24(1), 1-13.

Jamaludin, M.F., Ahmad, A.M., Mohammad, A. \& Shobri, N.D.M. (2016) A Study on the relationship between fun at work and work engagement. Proceedings of the ASEAN Entrepreneurship Conference.

Jena, L.K, Pradhan, S. (2017) Research and recommendations for employee engagement: Revisiting the employee-organization linkage", Development and Learning in Organizations. An International Journal, 31(5), 17-19.

Joo, B.K, Lim, D.H, Kim, S. (2016) Enhancing work engagement: the roles of psychological capital, authentic leadership, and work empowerment. Leadership \& Organization Development Journal 37 (8): 1117-1134.

Kanik, G., Ishaq, A.D., Mridula, M. (2018) Job Satisfaction and Work Engagement: A study using private sector bank managers. Advances in Developing Human Resources, 20(1), 58-71.

Little, P., \& Little, B. (2006) Employee engagement: conceptual issues. Journal of Organisational Culture, Communications and Conflict, 10(1), 111-120.

Lockwood, N.R (2007). Leveraging employee engagement for competitive advantage: HR's strategic role. HR Magazine. 52(3), 1-11.

Macey, W.H., \& Schneider, B. (2008) The meaning of employee engagement. Industrial and Organisational Psychology. $1(1), 330$.

Mani, V. (2011) Analysis of employee engagement and its predictors. International Journal of Human Resource Studies. $1(2), 87-95$.

Markos. S. \& Sridevi, M.S., (2010) Employee engagement: the key to improving performance. International Journal of Business and Management, 5(12), 56-67.

May, D.R., Gilson, R.L. \& Harter, L.M. (2004) The psychological conditions of meaningfulness, safety and availability and the engagement of the human spirit at work. Journal of Occupational E Organisational Psychology, 77(13), 1137.

McBain, R. (2007). The practice of engagement, Strategic HR Review, 6(6), 16-19.

Millar, G., (2012). Employee Engagement: A New Paradigm. Human Resource Management International Digest, 20(2), 103-177.

Mowbray, P. K., Wilkinson, A., \& Tse, H. H. M. (2014) An integrative review of employee voice: Identifying a common conceptualization and research agenda. International Journal of Management Reviews, 17, 382-400.

Ogbonnaya, C., Daniels, K., Nielsen, K. (2017). How incentive pay affects employee engagement, satisfaction, and trust. Harvard Business Review.

Olaniyan, O.S, Hystad, S.W. (2016). Employees' psychological capital, job satisfaction, insecurity, and intentions to quit: the direct and indirect effects of authentic leadership. Revista de Psicologia del Trabajo y de las Organizaciones, 32(3), 163-171.

Osborne, S., Hammoud, M.S. (2017). Effective employee engagement in the workplace. International Journal of Applied Management and Technology, 16(1), 50-67.

Osibanjo, A. O. Salau, O. P, Falola, H. O \& Oyewunmi, A. E. (2016). Work place stress: Implication for organisational performance in a Nigerian public University. Business: Theory and Practice. 17(3), 261-269.

Organ, D.W., Posdakoff, P.M. \& MacKenzie, S.B. (2006) Organisational citizenship behaviour: its nature, antecedents, and consequences, Thousand Oaks, CA: Sage.

Olivier, A.L., \& Rothmann, S. (2007) Antecedents of work engagement in a multinational oil company. South African Journal of Industrial Psychology, 33(3), 49-56.

Peterson, C., Nansook, P., \& Seligman, M.E. (2005) Orientations to happiness and life satisfaction: full life versus the empty life. Journal of Happiness Studies, 6(2), 25-41.

Richman, A. (2006) Everyone wants an engaged workforce how can you create it? Workspan. 49(4), 36-39.

Robinson, D., Perryman, S., \& Hayday, S. (2004). The drivers of employee engagement, institute for employment studies: University of Brighton.

Saks, A.M. (2006) Antecedents and consequences of employee engagement. Journal of Managerial Psychology, 21(6), 600619.

Schneider, B., Macey, W.H., Barbera, K.M., Martin, N. (2009). Driving customer satisfaction and financial success through employee engagement, People and Strategy, 32(2), 22-27.

Schaufeli, W. B., \& Bakker, A. B. (2004). Job demands, job resources and their relationship with burnout and engagement: A Multi-Sample Study. Journal of Organisational Behaviour, 25(5), 293-315.

Seijts, G.H and Crim, D. (2006). What engages employees the most or the ten c's of employee engagement. Ivey Business Journal, 70(4), 1-5. 
Shaw, K. (2005). An engagement strategy process for communicators', Strategic Communication Management, 9(3), 2629.

Shuck, M.B., Rose, K. (2013) Reframing employee engagement within the context of meaning and purpose implications for HRD. Advances in Developing Human Resources, 15, 341-355.

Shuck, M.B., Rocco, T.S \& Albornoz, C.A. (2011) Exploring Employee Engagement from the Employee Perspective: Implications for HRD. Journal of European Industrial Training, 35(4), 300-325.

Shuck, B., \& Wollard, K. (2010). Employee Engagement \& HRD: A Seminal Review of the Foundations. Human Resource Development Review, 9(1), 89-110.

Soyars, M., Brusino, J. (2009) Essentials of Engagement. Training and Development, 63(3), 62-65.

Strumpfer, D.J.W. (2003) Resilience and Burnout: A Stitch That Could Save Nine. South African Journal of Psychology, 33(4), 69-79.

Suharti, L. \& Suliyanto, D. (2012) The Effects of Organisational Culture and Leadership Style toward Employee Engagement and Their Impacts toward Employee Loyalty. World Review of Business Research, 2(5), 128 - 139.

Stander, M.W., \& Rothmann, S. (2010) Psychological Empowerment, Job Insecurity, and Employee Engagement. South African Journal of Industrial Psychology. 36(1), 1-8.

Wagner, R., \& Harter, J.K. (2006) The Great Elements of Managing. The Gallup Organisation, Washington, D.C.

Witemeyer, H.A. (2013) Employee Engagement Construct and Instrument Validation. Georgia State University, Atlanta.

Woodruffe, C. (2006) Employee Engagement: The Real Secret of Winning a Crucial Edge over Your Rivals. British Journal of Administrative Management. 50, 28-29.

Xu, J. \& Thomas, H.C. (2011) How Can Leaders Achieve High Employee Engagement? Leadership and Organisation Development Journal. 32(4), 399-416. 